\title{
Percutaneous Endovascular Treatment of Stenosis of Dialysis Arteriovenous Fistulas
}

\author{
Jagadeesh Pasupuleti ${ }^{\circledR 1}$, Yugandhar Samireddypalle ${ }^{\circledR 2}$, Saripudi S V N P Manikanta Vijay ${ }^{\circledR 3}$, Guntaka Srujana ${ }^{\circledR 3}$, Amitha Vikrama KS ${ }^{\circledR 4}$ \\ ${ }^{1}$ Post graduate, Department of Radiology, Narayana medical college, Nellore, Andhra Pradesh, India, ${ }^{2}$ Senior resident, Interventional Radiologist, Department of \\ Radiology, Narayana Medical College, Nellore, Andhra Pradesh, India, ${ }^{3}$ Post graduate, Department of Radiology, Narayana Medical College, Nellore, Andhra Pradesh, \\ India, ${ }^{4}$ Head, Department of Radiology, Bannerghatta Road, Bangalore, Karnataka, India.
}

\section{Abstract}

Background: The incidence of end stage renal disease is on the rise and most of these patients are undergoing dialysis either through tunneled/non tunneled dialysis catheters or through arteriovenous fistulas. The dialysis grafts and fistulas have limited durability of about 3 years and are more prone for thrombosis and stenosis, resulting in AVF dysfunction. As the number of access sites for dialysis is limited, percutaneous endovascular management by fistuloplasty has become the accepted first line of management to increase the lifespan of these fistulas.This article discusses a series of cases of AVF dysfunction secondary to draining vein stenosis managed by percutaneous transluminal angioplasty, their outcome and short term follow up till 3 months. The aim of the study is to review the role of percutaneous endovascular management of stenosis of dialysis fistulas, its indications, safety, efficacy and short term patency. Subjects and Methods: This was a prospective observational study done in department of Radio diagnosis, Narayana medical college, Nellore. About 20 cases were performed in our institution from December 2018 to August 2019. All these cases were done in angio suite after proper dialysis through temporary catheter. Post procedure doppler was done to evaluate the improvement in flow rate of these fistulas. Results: Seventeen cases were successful with immediate restoration of optimal flow rate during dialysis. (One case developed acute thrombosis of the fistula within 24 hours post procedure, which was successfully treated by needle directed thrombolysis with good patency at three month follow up). In two cases, there was failure of the procedure as the tight stenotic segment could not be negotiated. One case had early re-stenosis of the draining vein which required repeat session of fistuloplasty within one month with occlusion of the draining vein on three month follow up. Conclusion: Fistuloplasty is a minimally invasive percutaneous procedure with established safety and efficacy to restore the normal function of dialysis fistulae/grafts. The main aim of the procedure is to restore a diameter of the draining vein adequate for optimal flow rate during dialysis. Careful patient selection is required for increasing the success rate of the procedure. Repeat sessions of angioplasty is offered for re-stenosis to increase the lifespan of fistulas. Stent placement is usually avoided except for recurrent focal stenosis in precious fistulas.

Keywords: Areterio Venous Fistula, Arterio Venous Graft, Hemodialysis, Peritoneal dialysis, Peak systolic velocity.

Corresponding Author: Yugandhar Samireddypalle, Senior resident, Interventional Radiologist, Department of Radiology, Narayana Medical College, Nellore, Andhra Pradesh, India.

E-mail: research.nmch@rediffmail.com

Received: 16 December 2019

Revised: 22 January 2020

Accepted: 03 February 2020

Published: 29 April 2020

\section{Introduction}

There is increased incidence of end stage renal disease and the mainstay of management of these patients is through regular haemodialysis or peritoneal dialysis. Haemodialysis is much safer and more preferred to peritoneal dialysis. Haemodialysis is performed either through tunnelled /non tunnelled dialysis catheters or through arteriovenous fistulas/grafts. Based on age of kidney failure, between $23 \%$ and $51 \%$ of patients after starting dialysis will have an additional life expectancy of 10 years. ${ }^{[1]}$ Long-time preservation of dialysis sites is important for prolonged management of patients due to limited vascular access sites.

Various advantages of Arteriovenous fistulas over synthetic grafts are less infections, better patency, low risk of vascular steal syndrome, and decreased morbidity rates due to the surgical intervention during shunt creation. ${ }^{[2]}$ The National Kidney Foundation Dialysis Outcomes Quality Initiative (NKFDOQI) clinical practice guidelines has recommended recently that, ultimately, $40 \%$ of patients undergoing haemodialysis, should have an arteriovenous fistula. ${ }^{[3]}$

Common modalities for treatment of patients with kidney failure, before kidney transplantation, are hemodialysis (HD) 
and peritoneal dialysis (PD). A vascular access site which can be either an arteriovenous fistula (AVF) or arteriovenousgraft $(A V G)$ or venous catheter is required for the application of HD. Arteriovenous (AV) fistulas are usually the first choice for vascular access in those undergoing HD, as they are more durable and have decreased risk for infection in comparison with AVGs. If Ultrasound shows that vessels are not suitable for AVF, then an AVG is tried. The temporary venous catheters are usually used for access until the placement of AVF or AVG. Permanent tunneled venous catheters are the last access when a patient has lost all the possible sites for an AVF or AVG. ${ }^{[4]}$

These dialysis grafts and fistulas have limited durability of about 3 years and are more prone for thrombosis and stenosis, resulting in AVF dysfunction.

Percutaneous Endovascular management by fistuloplasty has become the first line of management to increase the lifespan of these fistulas/ grafts. ${ }^{[5]}$

\section{Subjects and Methods}

About 20 cases were performed in our institution from December 2018 to August 2019. All these cases were done in angio suite after proper dialysis through temporary catheter. Post procedure doppler was done to evaluate the improvement in flow rate of these fistulas.

These fistulas were followed up by Doppler for a period of 3 months post procedure.

\section{Inclusion criteria}

All patients who undergo suboptimal dialysis and have

- Dampened thrill on clinical examination.

- Poor dialysis flow rates.

- Doppler study showing outflow vein stenosis.

\section{Exclusion criteria}

- Virgin fistulas with poor thrill.

- Cellulitis of the dialysis limb.

- Concomitant venous pseudoaneurysms.

\section{Procedure}

After thorough pre procedure work up, written informed consent explaining in detail about the planned procedure was taken from the patient before the procedure.

The patient was shifted to angio suite and the dialysis limb is draped.

Draining vein access with retrograde cannulation is the usual preferred route for angioplasty and is done under ultrasound guidance. Arterial access with antegrade cannulation is attempted if the vein is collapsed distally.
Angiogram was taken and the stenotic segment is negotiated with MPA catheter and 035 Terumo wire followed by angioplasty with $5 \mathrm{~mm}$ or $6 \mathrm{~mm}$ over the wire non-compliant balloon, depending upon the average vein diameter.

We performed 3 minute inflation of the balloon at the plasty site and the second session of plasty was performed, only if there is more than $50 \%$ recoiling at the stenosis site.

014 wires are used for negotiating tight stenosis followed by angioplasty with coronary balloon

Post fistuloplasty the venous access is closed by purse string suture of the overlying skin, whereas the arterial access is closed by compression for 10 minutes.

The result of angioplasty is directly tested with intraoperative angiography and can be also clinically examined after the procedure. ${ }^{[5]}$

\section{Results}

Seventeen cases were successful with immediate restoration of optimal flow rate during dialysis. (One case developed acute thrombosis of the fistula within 24 hours post procedure, which was successfully treated by needle directed thrombolysis with good patency at three month follow up).

In two cases, the procedure was failure as the tight stenotic segment could not be negotiated.

One case had early re-stenosis of the draining vein which required repeat session of fistuloplasty within one month with occlusion of the draining vein on three months follow up.

\section{Complications}

The most dreaded complication is rupture of the artery at the anastomotic site due to angioplasty. This can be avoided by careful placement and dilatation of balloon at the juxta anastomotic site. Ultrasound can be used for the same purpose for additional safety.Other complications are the formation of pseudoaneurysms, acute thrombosis and periprocedural bacteremia. ${ }^{[6]}$

\section{Case 1 [Figure 1-3]}

\section{Case 2 [Figure 4-6]}

\section{Discussion}

End-stage renal disease is a common condition causing significant morbidity and mortality. There are three methods of long-term hemodialysis most commonly used; arteriovenous fistulas (AVFs), arteriovenous grafts (AVGs), and tunneled dialysis catheters. A well-functioning AVF provides good quality dialysis and is a lifeline for the patient. National and international guidelines recommend the native AVF as the preferred hemodialysis access owing to its lower morbidity 


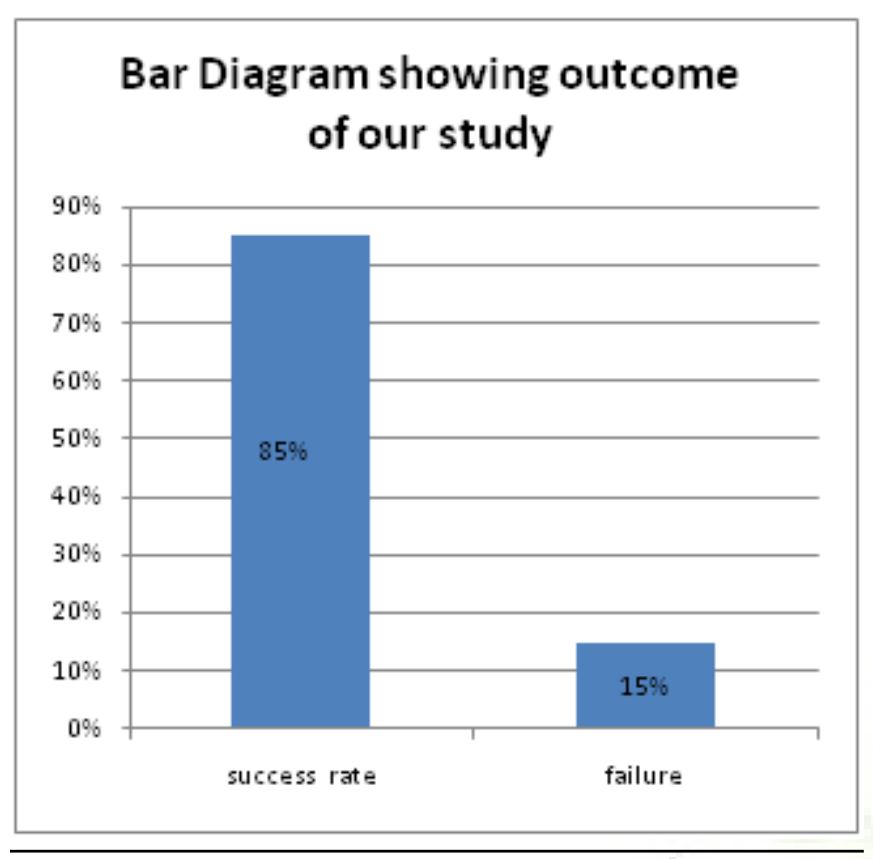

Graph 1: Outcome of the study

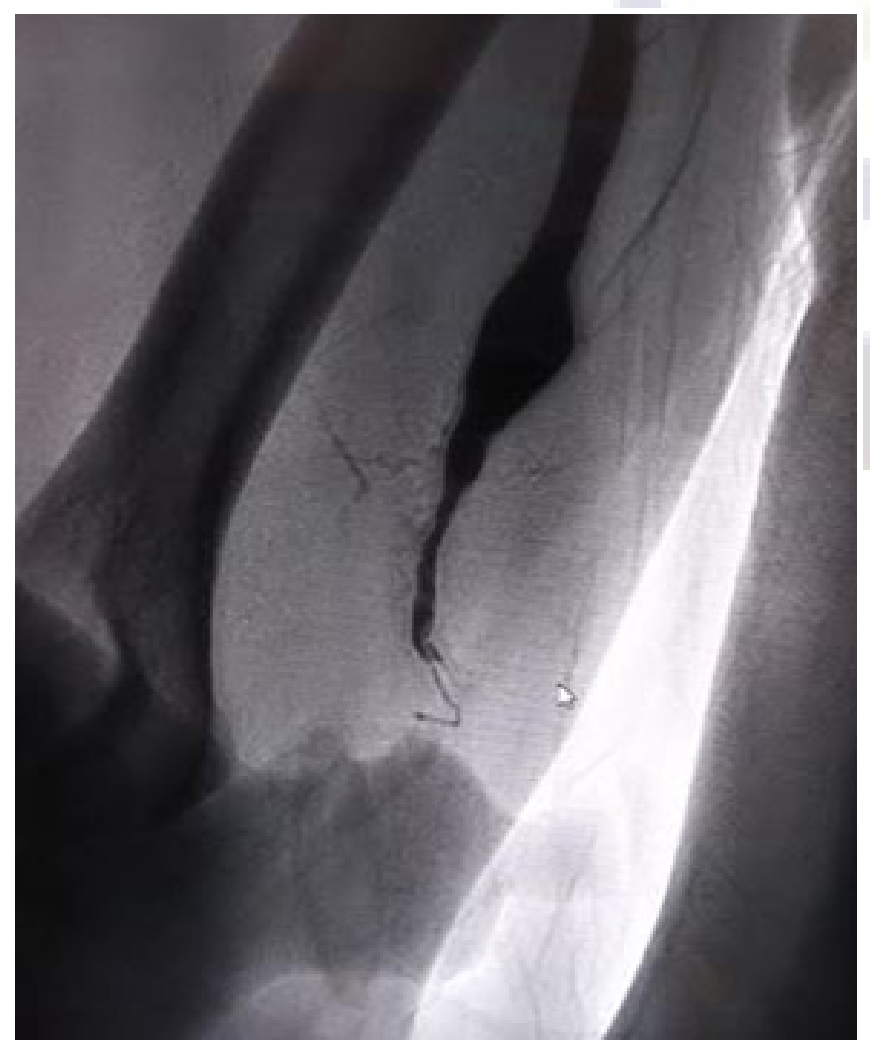

Figure 1: Retrograde venogram through cephalic vein demonstrates marked stenosis of the juxta anastomotic draining vein

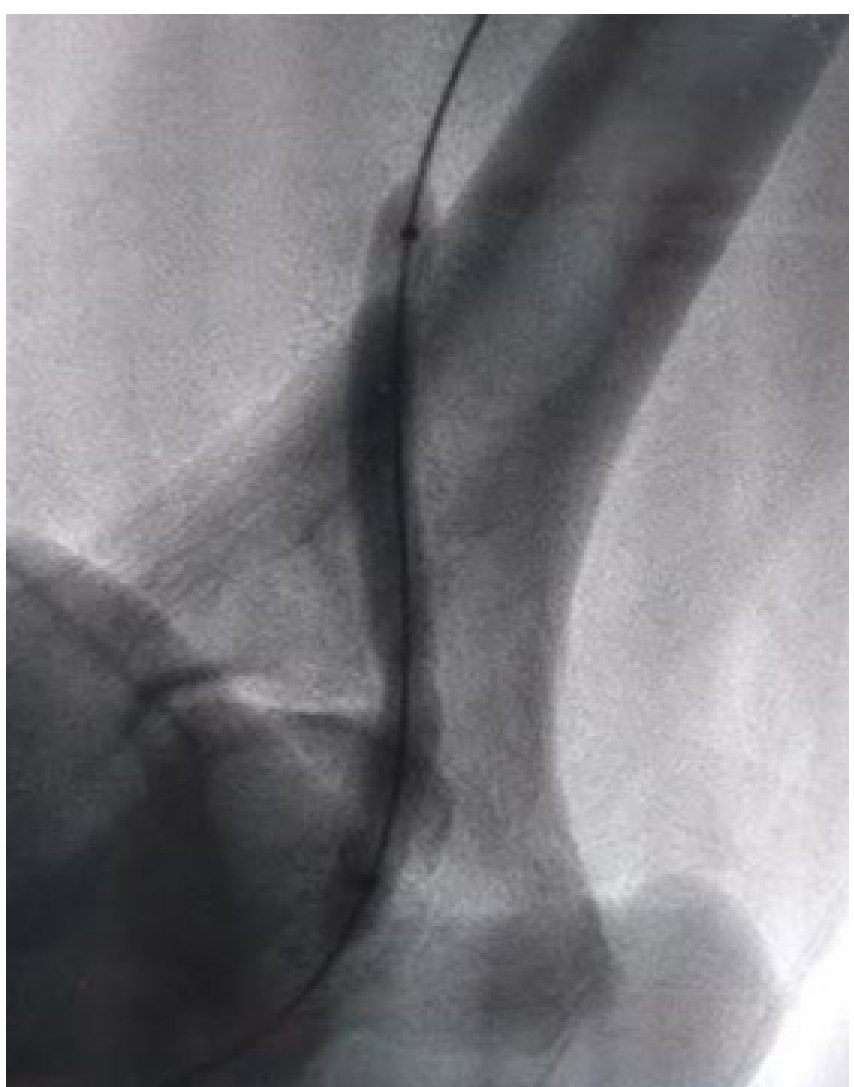

Figure 2: Fistuloplasty of the stenotic segment with $6 \mathrm{~mm}$ x $40 \mathrm{mmnnon}$-compliant balloon at $10 \mathrm{~atm}$ pressure

and mortality rates when compared with synthetic AVGs and catheter dialysis access.

AVF dysfunction is either primary, due to failure of fistula maturation or secondary, which is due to acute thrombosis of draining vein or venous outflow stenosis. The development of peripheral vein stenosis is the primary cause of fistula and graft thrombosis. The formation of stenosis is initiated by endothelial cell injury which leads to smooth muscle proliferation and neointimal hyperplasia.

The following factors may lead to endothelial injury:

- Shear stress from turbulent blood flow,

- Mechanical trauma from venipuncture, and angioplasties.

The most common site for stenosis in grafts occurs at the graft-vein anastomosis in $80 \%$ to $85 \%$ of the time followed by intragraft stenosis $11 \%$ to $15 \%$ and the graft-artery anastomosis $2 \%$ to $5 \%$ of the time. Fistulas tend to develop stenosis most commonly either at the juxta-anastomotic site and the outflow vein $(70 \%-85 \%)$. In the remaining $15 \%$ to $30 \%$ of the time, the lesion develops on the arterial site, which includes the feeding artery and anastomosis. ${ }^{[7]}$ 


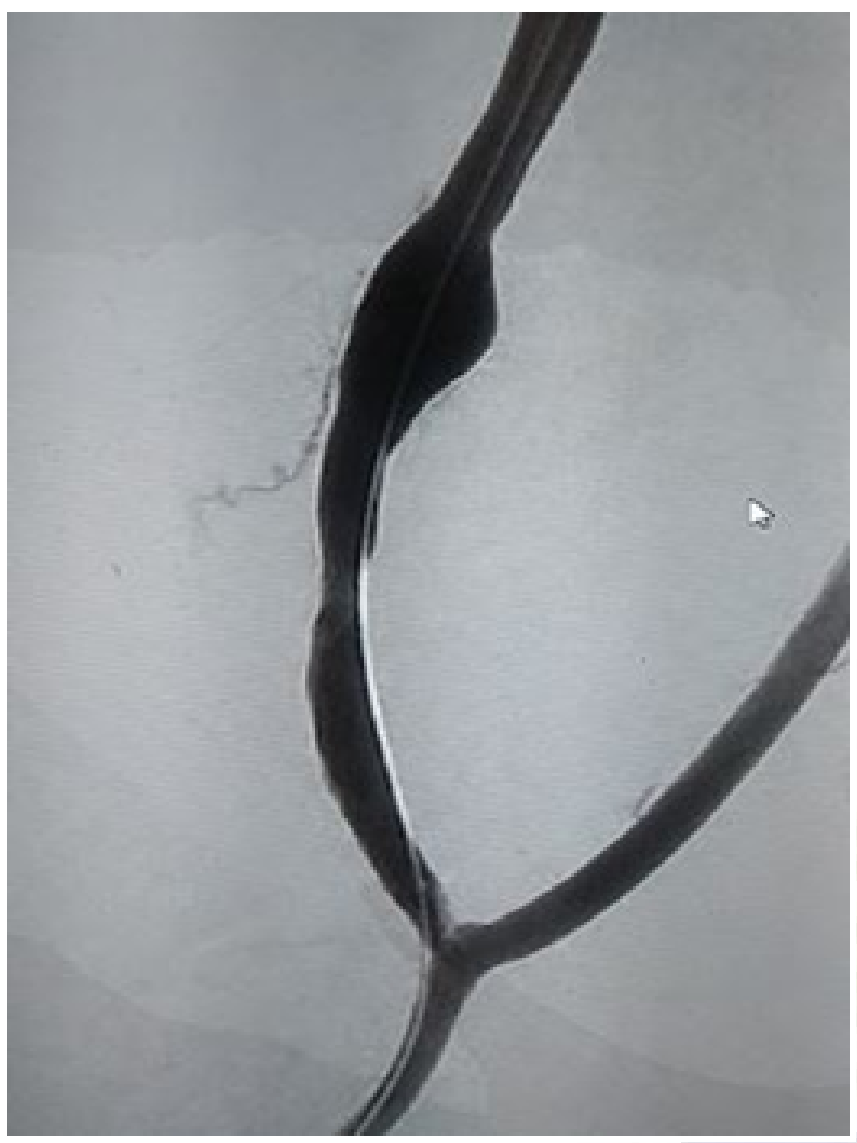

Figure 3: Post fistuloplasty angiogram demonstrating complete dilatation of the stenotic segment upto the fistula site

A hemodynamically significant stenosis leading to dialysis fistula dysfunction is associated with an increased rate of fistula thrombosis along with significant morbidity.

The patients with AVF dysfunction was referred to intervention radiology department for evaluation. Doppler study was done to evaluate the site of stenosis in these patients.

During Doppler examinations, the patient positioning was most often supine, with the arm relaxed and extended out to the side, with the area to be evaluated closest to the sonographer. The patient may be positioned in a Trendelenburg position with hands over the head or examined in the sitting position. Patient position should be optimized so that gravity helps dilate the veins. Doppler examinations were performed using linear arraystransducers $(5-10 \mathrm{MHz})$. Examination included the afferent artery, site of anastomosis, the draining veins as far as the subclavian vein as well as the arterial tree distal to the AVF in cases experiencing steal syndrome.All vessels were examined in both transverse and longitudinal planes using gray-scale and color images. At first, the vessels were

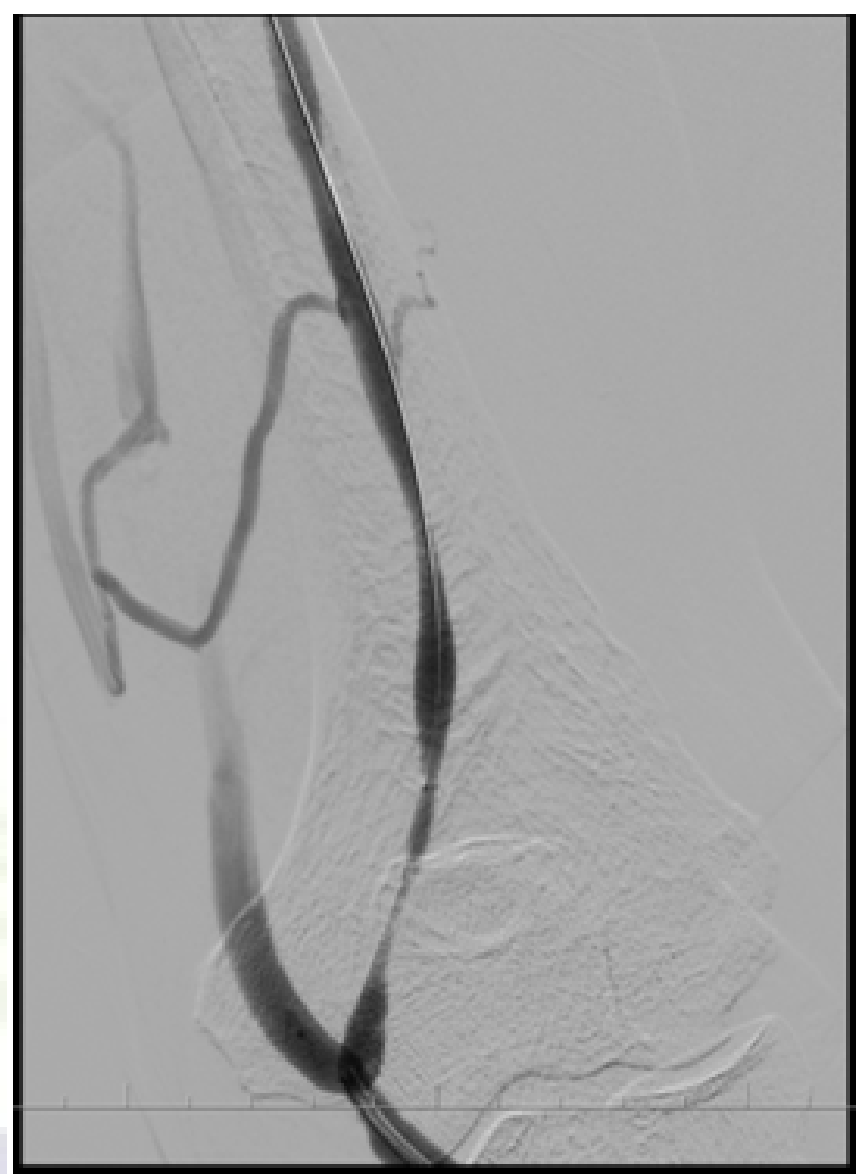

Figure 4: Retrograde venogram through cephalic vein demonstrating marked stenosis of the juxta anastomotic draining vein

examined by B-mode to determine the site and type of the fistula, detection of wall echo pattern and dilatations, and measurement of the vessel's diameter. Then color Doppler was performed to assess the direction of blood flow. The wall filter was set at $50-100 \mathrm{~Hz}$; and the sample size was maintained below $5 \mathrm{~mm}$ and was located at the center of each vessel. The spectral waveform was angle corrected, and the Doppler angles of incidence were less than $60^{\circ}$. Then spectral waveforms were obtained at each level.

The following parameters were measured at the site of the afferent artery and AV anastomosis: the arterial diameter $2 \mathrm{~cm}$ proximal to the site of fistula and diameter of the fistula, peak systolic velocity (PSV), and end diastolic velocity (EDV). Then examination of proximal, mid, and distal outflow vein for diameters, patency, and mean velocities was performed. In the presence of stenosis, the degree of the stenosis was calculated. Waveforms and PSVs were documented in any area where velocity increase or turbulence was noted. Stenosis 


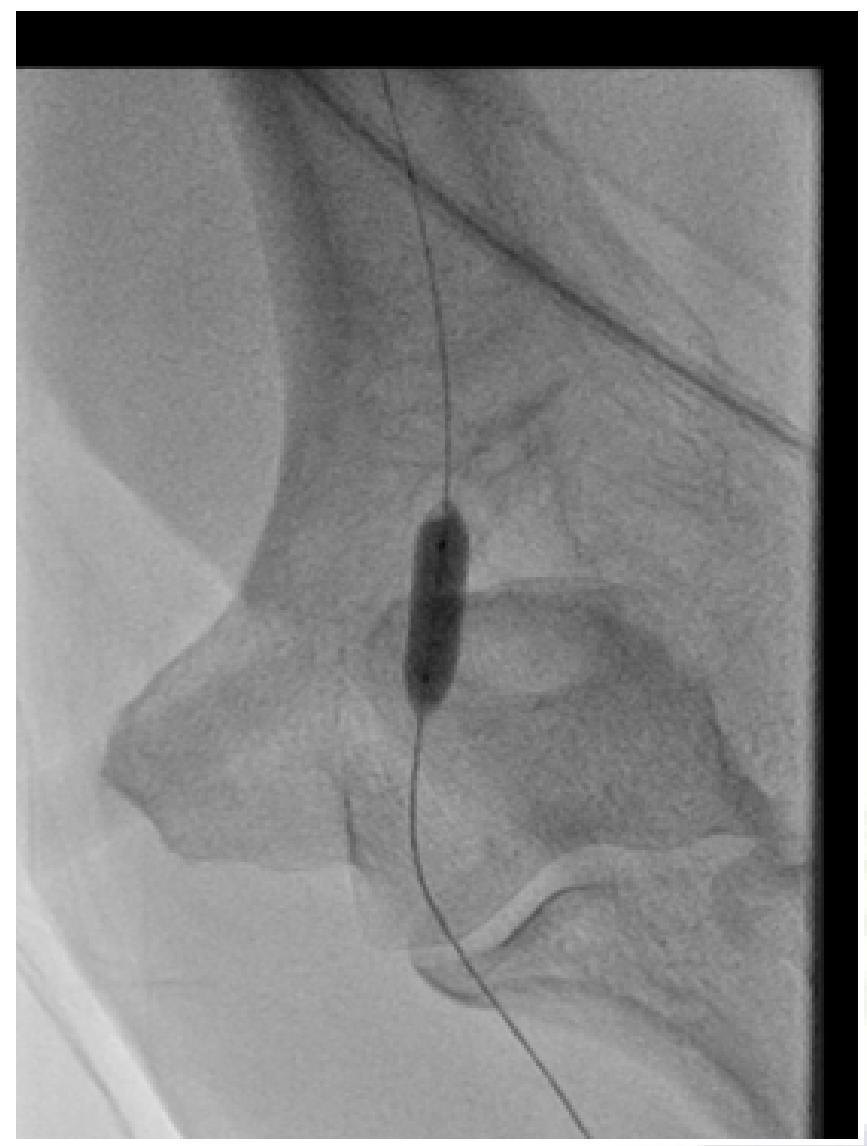

Figure 5: Fistuloplasty of the stenotic segment performed with $3.5 \times 10 \mathrm{~mm}$ coronary balloon

was diagnosed when there were reduction of the vessel diameter of more than $50 \%$ and an increase in PSV ratio (PSV in the stenotic area/ PSV upstream the stenotic area) greater than 2: 1 in the draining vein or greater than 3: 1 in the anastomotic area. ${ }^{[8]}$

Colour Doppler ultrasound characteristics of haemodynamically relevant stenoses. ${ }^{[9]}$

\section{Direct characteristics at the area of narrowing:}

- Luminal diameter reduction $>50 \%$

- Peak systolic flow velocity $>400 \mathrm{~cm} / \mathrm{s}$

- Pronounced aliasing phenomenon

- Indirect characteristics at the feeding artery

- High resistance Doppler waveform

- Reduction in access flow volume.

The etiologic mechanism of juxtaanastomotic stenosis is unclear, but multiple hypotheses exist. These hypotheses include the loss of the vasa venosum during skeletonization for mobilization of the most peripheral part of the vein,

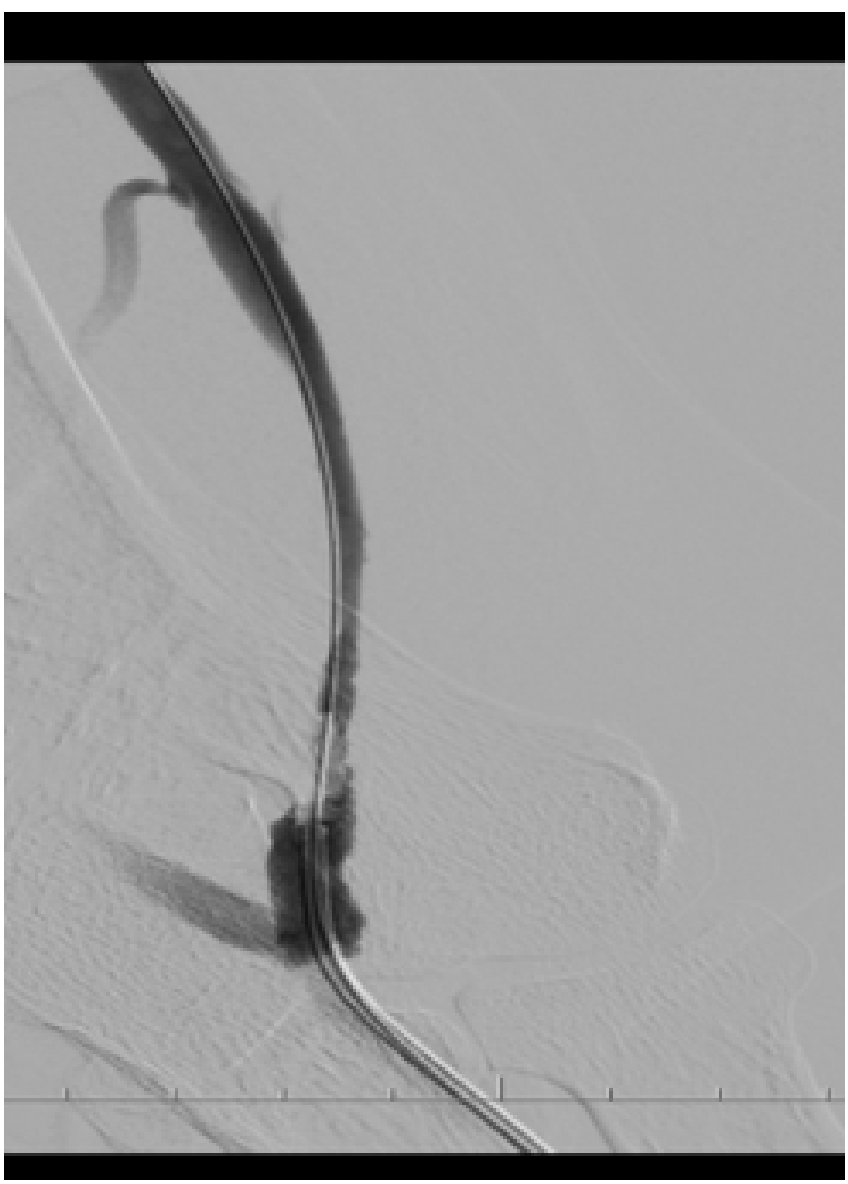

Figure 6: Post fistuloplasty angiogram demonstrating dilatation of the stenotic segment optimal for normal flow rate during fistula. Residual clots were seen (asterisk) which were resolved on heparin

low and fluctuating shear stress at this location, kinking, increased turbulence of the vein just downstream from the anastomosis and torsional stress. A combination of some or all of these stresses on this segment of vein leads to intimal injury with a subsequent cascade of proinflammatory cytokines. This cascade of proinflammatory cytokines leads to the proliferation of smooth-muscle cells, myofibroblasts, and an extracellular matrix that result in neointimal hyperplasia and subsequent stenosis. ${ }^{[10]}$ The other site is at the arterial and venous puctures, which are usually due to irritation by puncture needle tip.

In our experience, there are two common sites of draining vein stenosis. One is the juxta anastomotic site, which is usually secondary to neointimal hyperplasia. The other site is at the arterial and venous puctures, which are probably due to irritation by puncture needle tip. 
We reviewed various studies available in literature for success rates of percutaneous transluminal angioplasty in AVF dysfunction due to draining vein stenosis.

In Beathard GA et al, there was 94\% success rate and $6 \%$ failure rate for fistuloplasty. ${ }^{[11]}$

In study done by Thomas M. Vesely et al, The technical or immediate success of an angioplasty procedure ranges from $80 \%-98 \%$. Kanterman et al. reported decreasing patency rates for repeated dilation of a venous stenosis. ${ }^{[12]}$

In Gillan Irani et al study, there was no significant difference in anatomic success rate between the Drug eluting Ballon PTA and Conventional PTA groups $(89.9 \%$ and $78.3 \%$, respectively; Both groups exhibited $100 \%$ clinical success rates. ${ }^{[13]}$

In Andrew R. Forauer et al study, between 1 minute and 3 minute inflation balloon angioplasty,technical success rates in the 1- and 3-minute inflation groups were $75 \%$ and $89 \%$, respectively. ${ }^{[14]}$

In Ayse Aktas et al study revelaes PTA was technically successful in $96.3 \%$ of the stenoses. Clinical success was achieved in $97.2 \%{ }^{[15]}$

In Susana Machado et al study, the immediate success rate was $91 \%$ for arteriovenous fistulae and $83 \%$ for arteriovenous graft stenosis. Partial success was obtained in $11 \%$ of angiographies. The complication rate was $7 \% .{ }^{[16]}$

The role of metallic stent placement in the peripheral outflow veins in hemodialysis patients is controversial. Most of the articles concerning clinical application of metallic stent in hemodialysis patients reported the treatment of central venous lesions or peripheral lesions in graft patients. Metallic stent usage in peripheral lesions in graft patients has been associated with high success rates. Only a few articles described metallic stent placement in native AV fistulas and in only a small number of patients. The primary and secondary patency rates were $57 \%$ and $83 \%$, respectively at 6 months, and $29 \%$ and $53 \%$, respectively at the end of the first year. But, the patient population was small, and the indication for stent placement was unclear. ${ }^{[17]}$

We performed intervention for mature fistulas which have undergone at least 5 sessions of dialysis. Virgin fistulas were excluded in our study. We have performed angioplasties using plain non-compliant balloons. No drug eluting balloons were used in our study.

We perfomed a standard 3 minute inflation of the balloon at the stenotic site and repeat the plasty for second time, if there is recoiling of more than $50 \%$.

Failure was considered as restenosis within 10 sessions of dialysis.
In our study, seventeen cases were successful with immediate restoration of optimal flow rate during dialysis. One case developed acute thrombosis of the fistula within 24 hours post procedure, which was successfully treated by needle directed thrombolysis with good patency at three month follow up.

We believe this could be due to intimal injury post angioplasty. This stresses the need of considering functional improvement in flow rates as technical success of the procedure, rather than cosmetic angiogram result.

In two cases, the procedure was failure as the tight stenotic segment could not be negotiated. These stenotic sites were at the arterial puncture site.

One case had early re-stenosis of the draining vein which required repeat session of fistuloplasty within one month with occlusion of the draining vein on three month follow up. This stenosis was at the arterial puncture site. We advised for stent placement in the third setting, however, the patient was lost to further follow up.

The percutaneous angioplasty is an efficacious method for the treatment of stenosis of arteriovenous fistulae for hemodialysis and constitutes another therapeutic option.

In recent years, several studies have demonstrated that angioplasty is efficacious with some advantages compared to the conventional surgical treatment such as a shorter time needed to perform the procedure and shorter hospitalization, less discomfort for the patient, and lower infection rates. Additionally, it enables dialysis immediately after the procedure without the necessity of using a central venous catheter. ${ }^{[6]}$

The current study confirms these findings and suggests this therapeutic approach as best option for stenosis of arteriovenous fistulae.

In our study, one complication occurred: one case of acute thrombosis of the fistula after angioplasty, for which needle directed thrombolysis was offered and had good short term patency rate.

All Patients were kept on Subcutaneous Heparin up to 48 hours post procedure.

Post procedure Doppler was performed to document increase in the volume flow of the fistula. Dialysis through the fistula was allowed only after documentation of near total recanalisation of the draining vein with less than $10 \%$ of residual thrombosis.

\section{Patient follow-up}

There is a high rate of restenosis and repeat treatments after endovascular interventions in AV access stenoses. Follow-up of patients is therefore important to ensure a good clinical and technical result after PTA and for prompt detection of dialysis access dysfunction. [5] Follow-up with clinical assessment of the AVF and Doppler was performed in our patients upto three 
months post procedure.

\section{Conclusion}

Fistuloplasty is a minimally invasive percutaneous procedure with established safety and efficacy to restore the normal function of dialysis fistulae/grafts.

It has become a standard therapy for the management of AVF dysfunction, because it is safe, effective, and easily performed, there by prolonging the patency of the fistula and life span of the patient.

The main aim of the procedure is to restore a diameter of the draining vein adequate for optimal flow rate during dialysis. Careful patient selection is required for increasing the success rate of the procedure. Repeat sessions of angioplasty can be offered for re-stenosis to further increase the lifespan of fistulas. Literature for Stent placement in recurring draining vein stenosis is limited. The stent placement is usually avoided except for recurrent focal stenosis in precious fistulas.

\section{References}

1. Mailloux LU, Bellucci AG, Napolitano B, Mossey T, Wilkes BM, Bluestone PA. Survival estimates for 683 patients starting dialysis from 1970 through 1989: identification of risk factors for survival. Clin Nephrol. 1994;42(2):127-135.

2. Chazan JA, London MR, Pono LM. Long-Term Survival of Vascular Accesses in a Large Chronic Hemodialysis Population. Nephron. 1995;69(3):228-233. Available from: https://dx.doi.org/10.1159/000188461.

3. Eknoyan G, Levin N. NKF-K/DOQI Clinical Practice Guidelines: Update 2000. Foreword. Am J Kidney Dis. 2000;37((1 Suppl 1)):5-6.

4. Bountouris I, Kritikou G, Degermetzoglou N, Avgerinos KI. A Review of Percutaneous Transluminal Angioplasty in Hemodialysis Fistula. Int J Vasc Med. 2018;2018:1-5. Available from: https://dx.doi.org/10.1155/2018/1420136.

5. Steiner K, Dutta P, Stempel CV, Walton H, H. Percutaneous transluminal angioplasty in arteriovenous fistulas: current practice and future developments. J Radiol Nurs. 2017;36(3):145151. Available from: https://doi.org/10.1016/j.jradnu.2017.04. 014.

6. Miquelin DG, Reis LF, da Silva AAM, de Godoy JMP. Percutaneous transluminal angioplasty in the treatment of stenosis of arteriovenous fistulae for hemodialysis. Int Arch Med. 2008;1(16):1-4. Available from: https://dx.doi.org/10. 1186/1755-7682-1-16.

7. MacRae JM, Dipchand C, Oliver M, Moist L, Lok C, Clark E, et al. Arteriovenous access failure, stenosis, and thrombosis. Can J Kidney Health Dis. 2016;3:1-11. Available from: https: //dx.doi.org/10.1177/2054358116669126.

8. Abdelaziz O, Fahmy MA, El-Khashab SO. Role of color doppler ultrasound for assessment of arteriovenous fistula dysfunction in hemodialysis patients. Kasr Al Ainy Med J. 2018;24(2):72-78. Available from: https://dx.doi.org/10.4103/ kamj.kamj_2_18.
9. Wiese P, Nonnast-Daniel B. Colour Doppler ultrasound in dialysis access. Nephrol Dial Transplant. 2004;19(8):19561963. Available from: https://doi.org/10.1093/ndt/gfh244.

10. Quencer KB, Arici M. Arteriovenous Fistulas and Their Characteristic Site of Stenosis. Am J Roentgenol. 2015;205(4):726734. Available from: https://dx.doi.org/10.2214/ajr.15.14650.

11. Beathard GA. Percutaneous transvenous angioplasty in the treatment of vascular access stenosis. Kidney Int. 1992;42(6):1390-1397. Available from: https://doi.org/10. 1038/ki.1992.431.

12. van der Linden J, van den Dorpel MA. Percutaneous Transluminal Angioplasty of Failing Hemodialysis Grafts and Fistulae. Saudi J Kidney Dis Transpl. 2004;15(3):333-337. Available from: http://www.sjkdt.org/text.asp?2004/15/3/333/ 32982.

13. Irani FG, Teo TKB, Tay $\mathrm{KH}$, Yin $\mathrm{WH}$, Win $\mathrm{HH}$, Gogna A, et al. Hemodialysis arteriovenous fistula and graft stenoses: randomized trial comparing drug-eluting balloon angioplasty with conventional angioplasty. J Vasc Interv Radiol. 2018;289(1):238-285. Available from: https://doi.org/ 10.1148/radiol.2018170806.

14. Forauer AR, Hoffer EK, Homa K. Dialysis Access Venous Stenoses: Treatment with Balloon Angioplasty-1- versus 3minute Inflation Times. Radiology. 2008;249(1):375-381. Available from: https://dx.doi.org/10.1148/radiol.2491071845.

15. Aktas A, Bozkurt A, Aktas B, Kirbas I. Percutaneous transluminal balloon angioplasty in stenosis of native hemodialysis arteriovenous fistulas: technical success and analysis of factors affecting postprocedural fistula patency. Diagn Interv Radiol. 2015;21(2):160-166. Available from: https://dx.doi. org/10.5152/dir.2014.14348.

16. Machado S, Ferreira A, Lucas C, Gil C, Fortes A, Neves FC. Results of endovascular procedures performed in dysfunctional arteriovenous accesses for haemodialysis. Port J Nephrol Hypert. 2012;26(4):266-71. Available from: http://www.scielo.mec.pt/scielo.php?script=sci_arttext\&pid= S0872-01692012000400005.

17. Özkan B, Güngör D, Yıldırım UM, Harman A, Özen Ö, Aytekin C. Endovascular Stent Placement of Juxtaanastomotic Stenosis in Native Arteriovenous Fistula After Unsuccessful Balloon Angioplasty. Iran J Radiol. 2013;10(3):133-139. Available from: https://dx.doi.org/10.5812/iranjradiol.11386.

Copyright: (C) the author(s), 2020. It is an open-access article distributed under the terms of the Creative Commons Attribution License (CC BY 4.0), which permits authors to retain ownership of the copyright for their content, and allow anyone to download, reuse, reprint, modify, distribute and/or copy the content as long as the original authors and source are cited.

How to cite this article: Pasupuleti J, Samireddypalle Y, Vijay SSVNPM, Srujana G, Vikrama KS A. Percutaneous Endovascular Treatment of Stenosis of Dialysis Arteriovenous Fistulas. Asian J. Med. Radiol. Res. 2020;8(1):21-27.

DOI: dx.doi.org/10.47009/ajmrr.2020.8.1.4

Source of Support: Nil, Conflict of Interest: None declared. 